\title{
La prisión preventiva y sus límites*
}

Esperanza Sandoval Pérez**

RESUMEN: Con la implementación del sistema de justicia penal en México, la presunción de inocencia deja de ser un principio para convertirse en un derecho fundamental del imputado frente al ejercicio del poder punitivo del Estado, garantizado en la Constitución Federal, en el ordenamiento adjetivo y leyes especiales penales; constituyendo uno de los límites de la prisión preventiva que en este trabajo se aborda en dos vertientes: la primera para explicar si la imposición de esta medida cautelar viola ese derecho y la segunda, para conocer los fines y el trato de los presos provisionales a la luz de la Ley Nacional de Ejecución Penal.

Palabras clave: prisión preventiva, presunción de inocencia, procedimiento abreviado, preso provisional.
ABSTRACT: With the implementation of the criminal justice system in Mexico, the presumption of innocence ceases to be a principle to become a fundamental right of the accused against the exercise of the punitive power of the State, guaranteed in the Federal Constitution, in the adjective order and special criminal laws; constituting one of the limits of pre-trial detention that is addressed in two aspects in this work: the first to explain whether the imposition of this precautionary measure violates that right and the second, to know the purposes and treatment of provisional prisoners in the light of the National Law on Criminal Execution. Keywords: pre-trial detention, presumption of innocence, abbreviated procedure, provisional prisoner.

SUMARIO: Introducción; 1. Prisión preventiva; 2. Límites; 3. Casos de procedencia; 4. Finalidad; 5. Excepciones; 6 . El preso provisional. Conclusiones. Fuentes de consulta.

\section{Introducción}

El derecho a no ser privado de la libertad personal, sino en virtud de mandamiento dictado por la autoridad judicial y de conformidad con las causas autorizadas en la Constitución Federal (Arts. 16 y 19) está íntimamente vinculado con la presunción de inocencia que anteriormente se analizó como principio de pleno reconocimiento en el ámbito penal nacional e internacional (Sandoval Pérez, 2017) y como la duda razonable en el juicio oral (Sandoval Pérez, 2016) y que a partir a partir de la reforma constitucional federal de 2008

\footnotetext{
* Artículo recibido el 25 de mayo de 2020 y aceptado para su publicación el 7 de julio de 2020.

** Doctorada en Derecho Público por el Instituto de Investigaciones Jurídicas y Académico de Tiempo completo en la Facultad de Derecho en la Universidad Veracruzana. Integrante del Sistema Nacional de Investigadores.
} 
se estudia como un derecho fundamental que asiste al imputado (Art. 20, B, fracción I) que podrá imponer el Juez de Control a petición del Ministerio Publico, de la víctima/ofendido, o bien oficiosamente en los casos previstos en el artículo 19, párrafo segundo in fine y en el numeral 155, Fracción XIV del Código Nacional de Procedimientos Penales como una medida cautelar de última ratio.

Con lo anterior retornan a la mesa de debates los posicionamientos doctrinales que por una parte consideran que su aplicación quebranta el derecho a la presunción de inocencia y por la otra parte, que se transgrede el derecho del imputado al admitir la responsabilidad del hecho penal como requisito para dar apertura al procedimiento abreviado en términos del artículo 201 del ordenamiento procesal penal ya citado.

El objetivo general se centra en aproximarse a la respuesta de dichos cuestionamientos, mientras que, en cuanto a la estructura metodológica requiere abordar el concepto y los límites de la prisión preventiva haciendo hincapié de sus efectos de frente al derecho de presunción de inocencia, fijando posición; los casos en que procede su aplicación, la finalidad y las excepciones de esta medida cautelar y el estatus de preso provisional. Se concluye y citan las referencias.

\section{Prisión preventiva}

El modelo de proceso penal de corte liberal construido sobre el concepto duda razonable, entendida como la existencia de incertidumbre racional sobre la verdad de la hipótesis de acusación

... cuando la hipótesis de la defensa es total o tendencialmente compatible con la hipótesis de la acusación, el hecho de que aquella se encuentre confirmada por las pruebas disponibles genera una incertidumbre racional sobre la verdad de la hipótesis sustentada por el Ministerio Publico, lo que se traduce en la existencia de una duda razonable sobre la culpabilidad del imputado ... (Jordi, 2005)

Lo anterior fortalece el Estado de derecho que descansa en un sistema equitativo de justicia frente a la arbitrariedad y el despotismo, con garantías para el imputado entrelazado la presunción de inocencia y el debido proceso, que en palabras de implica que al inculpado se le reconozca el derecho a su libertad, que el Estado sólo podrá privarlo de la misma, cuando existan suficientes elementos incriminatorios, se respete las formalidades esenciales del procedimiento; específicamente las garantías de audiencia y de ofrecer pruebas para desvirtuar la imputación correspondiente. Con sustento en lo anterior, el Juez pronuncie sentencia definitiva declarándolo culpable (Aguilar López, 2015).

Entre las disposiciones jurídicas más importantes sobre el origen de la prisión preventiva se encuentra:

a) El Pacto Internacional de Derechos Civiles y Políticos dice que es derecho de toda persona detenida o presa a causa de una infracción penal, ser llevada sin demora ante un juez u otro funcionario autorizado por la ley para ejercer funciones judiciales, quien tendrá derecho a ser juzgada dentro de un plazo razonable o a ser puesta en libertad. La prisión preventiva de las personas que hayan de ser juzgada, no debe ser la regla general, su libertad podrá estar subordinada a garantías que aseguren la comparecencia del acusado en el acto del juicio, o en cualquier otro momento de las diligencias procesales y, en su caso, 
para la ejecución del fallo (9.3).

b) La Convención Americana sobre Derechos Humanos al hacer referencia a la libertad personal dispone que toda persona detenida o retenida debe ser llevada, sin demora, ante un juez u otro funcionario autorizado por la ley para ejercer funciones judiciales y tendrá derecho a ser juzgada dentro de un plazo razonable o a ser puesta en libertad, sin perjuicio de que continúe el proceso. Su libertad podrá estar condicionada a garantías que aseguren su comparecencia en el juicio (artículo 7.5).

En doctrina la prisión preventiva es considerada una medida precautoria de índole personal que crea al individuo -sobre quien recae- un estado más o menos permanente de privación de su libertad física, soportada en un establecimiento público destinado al efecto, que es decretada por juez competente en el curso de una causa, contra el autor o partícipe de un delito previsto con pena privativa de libertad; con el único objeto de asegurar su presencia durante el juicio y garantizar la eventual ejecución de las penas (Zavaleta, 1954). Mellado citado por Morillas Cuevas, afirma que se trata de una medida cautelar de carácter personal, que se resuelve en la privación de la libertad de un sujeto investigado y que se adopta en el seno de un proceso penal por la autoridad judicial a los efectos de garantizar fines adecuados a la Constitución y previstos expresamente por la Ley y desprende de su concepto las notas esenciales siguientes:

1. Se resuelve en una privación de libertad que se cumple en un establecimiento penitenciario pero que queda sujeta a un régimen distinto al aplicable a los penados;

2. Es siempre jurisdiccional, no puede ser decretada por los particulares o por la autoridad gubernativa;

3. Tiene carácter provisional, pero se limita a unos plazos máximos, de modo que jamás puede extenderse más allá de ellos, al margen de la situación real del proceso y de que el mismo no haya concluido; $y$,

4. Tiende a cumplir unos concretos fines, no siempre estrictamente cautelares, pero que han sido estimados adecuados a la Constitución en tanto se considera que aseguran el proceso u otras finalidades legítimamente protegibles (Morillas Cuevas, 2016).

La prisión preventiva es la privación de la libertad ambulatoria que el Juez de Control aplica de manera excepcional al acusado de un delito en situaciones de necesidad extrema, en espera de la celebración del juicio y mientras dura éste, con el fin de prevenir eventuales acciones que puedan dañar a un tercero o la marcha del proceso. Tiene un carácter coercitivo provisional que afecta la libertad personal durante un breve periodo de tiempo, para garantizar que el procedimiento no sea obstaculizado interrumpido o demorado, pero no significa un adelanto de la condena pues no se recluye al imputado porque se crea que su responsabilidad es evidente. Esta medida constituye también un medio para garantizar el desarrollo del proceso penal con la presencia del imputado, con la posterior y eventual ejecución de la sentencia (Avalos, 2013).

Para Landrove Díaz la prisión provisional, en teoría representa una simple medida cautelar y transitoria de aseguramiento del proceso penal, pero esta se convierte, en realidad, en una condenada por adelantado, violadora del principio de presunción de 
inocencia, además de que prejuzga, en cierta medida En cuanto sea compatible con su situación procesal, los presos preventivos podrán acceder a las actividades educativas, formativas, deportivas que se celebren en el centro penitenciario, en las mismas condiciones que los penados (Landrove, 1984).

La prisión preventiva tiene como única misión retener y custodiar a los detenidos presos para ponerlos a disposición de la autoridad judicial, debiendo regir el principio de presunción de inocencia. La institución encierra un sofisma, considera el aislamiento preventivo como la primera vulneración a ese derecho, preguntándose además ¿̇por qué se encierra?, dando respuesta a lo cuestionado al decir que es en razón de que existe la presunción de culpabilidad justificada, que tiene como propósito mantener al presunto culpable a disposición de la justicia, ante el temor de su probable fuga, garantizándose con ello la presencia del imputado en el proceso, así como, la eventual ejecución penal (Pérez Cepeda, 2001).

La prisión preventiva produce la confrontación del derecho constitucional que tiene todo individuo a la presunción de inocencia, con la llamada "necesidad social" que la justifica; empero, en atención a los principios de un Estado Social y democrático de Derecho y cumpliendo en esta caso el mandato constitucional, las normas del régimen preventivo deberán de estar precedidas por la idea de intervención mínima, en el sentido que se establezcan solamente las limitaciones estrictamente imprescindibles (Morillas Cuevas, 2016).

\section{Límites}

La autoridad jurisdiccional no puede imponer libremente la prisión preventiva, pues sería una facultad absoluta, que está limitada por los principios de legalidad, presunción de inocencia, necesidad de la medida, de proporcionalidad a la gravedad del hecho que se imputa. Lo que se explica de la manera siguiente:

I. Principio de legalidad. Es básico del derecho penal, sustantivo y adjetivo y radica en la obligación del Estado de ajustar su actuación estrictamente a lo establecido por la ley elaborada previamente al hecho incriminado, de la manera más clara y precisa, sustentada en la necesidad de asegurar la teleología de su imposición en términos de lo previsto en el artículo 19, párrafo segundo, de la Ley Suprema que regula el carácter excepcional de la medida estableciendo la posibilidad de que el Ministerio Público la solicite al Juez cuando otras medidas cautelares no sean suficientes para garantizar la comparecencia del imputado en el juicio, el desarrollo de la investigación, la protección de la víctima, de los testigos o de la comunidad, así como cuando el imputado esté siendo procesado o haya sido sentenciado previamente por la comisión de un delito doloso, o de manera oficiosa en caso de que se impute uno de los delitos que en la parte ultima del mismo párrafo se relacionan.

II. Presunción de inocencia. El sustento garantista del Sistema de justicia penal en México respeta los derechos de la víctima/ofendido y del imputado señalado por el Ministerio Público como posible autor o participe de un hecho previsto en la ley como delito, quien es

considerado inocente hasta que no se demuestre su responsabilidad con prueba que aporte 
la parte acusadora para crear la convicción del juzgador necesaria para condenar (Art.20, B. I). La inocencia es un concepto de referencia que solo toma sentido cuando existe alguna posibilidad de que el imputado puede ser responsable, ya que la situación normal del ciudadano es de libertad, ámbito básico de toda persona, sin referencia al derecho procesal (Blinder, 2002).

Uno de los antecedentes más importantes de la prisión preventiva se encuentra en la Carta Magna Inglesa $(1215$,$) al establecer que ningún hombre libre será arrestado o$ detenido en prisión o privado de su tenencia libre o declarado fuera de la ley o desterrado o molestado de cualquier forma y no se procederá contra él ni se enviará a nadie en su contra, sino es por el juicio legal de sus pares y por la ley de la tierra (Clausulas 39 y 40).

El contenido anterior se incorpora a la Constitución de los Estados Unidos de Norteamérica (1787) como el principio due process of law, cuya traducción al español más conocida es debido proceso legal, que garantiza a los ciudadanos los derechos establecidos en las diez primeras enmiendas (Bill of Rights) entre ellos los siguientes: ser informado de la acusación, presunción de inocencia, a no confesarse culpable, la celeridad en el proceso y la legalidad.

En el Tratado sobre los Delitos y las Penas (1764), el apartado 16. De la tortura, dice que la tortura del reo para obligarlo a confesar un delito es una crueldad consagrada por el uso entre la mayor parte de las naciones, por no se cual metafísica e incomprensible purgación de infamia. Un hombre no puede ser llamado reo antes de la sentencia de un juez, ni la sociedad puede quitarle la protección, sino cuando este decidido que ha violado los pactos que les fue concedida. ¿Qué derecho, sino el de la fuerza será el que, de potestad al juez para imponerle pena a un ciudadano, mientras se duda si es reo o inocente? (Beccaria, 2015). Partiendo del pensamiento anterior, Carrara el más ilustre representante Escuela Clásica dice que:

Con la presunción de inocencia y con la negación de la culpa se protege a este hombre porque es inocente, así lo proclamo hasta que no hayáis probado su culpabilidad (...) con los modos y las forma que yo prescribo, y que debéis respetar porque ellas proceden también de dogmas de absoluta razón. (Carrara, 1999)

Todos reconocen que la privación de libertad de los imputados antes de su condena es una injusticia, porque por sospechas falaces demasiadas veces llega el tormento a las familias y se priva de libertad frecuentemente a ciudadanos honestísimos, y de las cuales el 60 por 100 al final del proceso o del término del juicio son posteriormente declarados inocentes..., la misma es una injusticia necesaria, por lo cual la custodia preventiva ha debido admitirse por las leyes penales para justificar el proceso escrito, alcanzar la verdad, necesaria para la seguridad y alcanzar la pena.

El estado de inocencia también se encuentra en el artículo $9^{\circ}$, de la Declaración de los Derechos del Hombre y del Ciudadano (Francia, 1789), el cual establece que deberá presumirse que todo hombre es inocente mientras no sea declarado culpable, si se juzga indispensable arrestarlo, todo rigor que no sea necesario para asegurar su persona debe ser severamente reprimido por la ley. Con ello, el programa político criminal determinó el futuro del encarcelamiento preventivo que surge para defender la vigencia de este 
principio, propicia que la fuerza inicial del iluminismo comenzara a perder su capacidad para enfrentarse a la más poderosa fuerza del estado, el derecho penal.

La Declaración Universal de los Derechos Humanos (ONU, 1948) es clara al establecer que toda persona acusada de delito tiene derecho a que se presuma su inocencia mientras no se pruebe su culpabilidad conforme a la ley y en juicio público en el que se le haya asegurado todas las garantías necesarias para su defensa (artículo 11). Mientras que el Pacto Internacional de Derechos Civiles y Políticos (1966) dispone que la libertad podrá estar subordinada a garantías que aseguren la comparecencia del acusado en el acto del juicio, o en cualquier otro momento de las diligencias procesales y, en su caso, para la ejecución del fallo (artículo 9.1-3).

Desde los inicios del siglo XXI, la Suprema Corte de Justicia de la Nación se expresó en el sentido de que el principio debido proceso legal implica que al inculpado se reconozca el derecho a su libertad y que el Estado sólo podrá privarlo de la misma cuando existan suficientes elementos incriminatorios, seguido un proceso penal en su contra en el que se respeten las formalidades esenciales del procedimiento, las garantías de audiencia y la de ofrecer pruebas para desvirtuar la imputación correspondiente, el Juez pronuncie sentencia definitiva declarándolo culpable; y, por la otra parte, el principio acusatorio, mediante el cual corresponde al Ministerio Público la función persecutoria de los delitos y la obligación (carga) de buscar y presentar las pruebas que acrediten la existencia de éstos; resguardando con ello en forma implícita el principio de presunción de inocencia, dando lugar a que el gobernado no esté obligado a probar la licitud de su conducta cuando se le imputa la comisión de un delito, en tanto que no tiene la carga de probar su inocencia (Suprema Corte de Justicia de la Nación, Tesis P. XXXV/2002).

De lo anterior se colige que la presunción de inocencia se resguarda mucho antes de la reforma constitucional federal de 2008, a través de los principios debido proceso legal y acusatorio que separa las funciones entre distintos organismos del Estado, de tal manera que la función investigadora y el ejercicio de la acción penal corresponde al Ministerio Público, la función jurisdiccional a los jueces y la ejecución de la pena, al Estado.

En un sistema democrático de derecho, el debido proceso es aquel en el cual se respetan las garantías procesales, las libertades de los ciudadanos, y las exigencias derivadas del principio de presunción de inocencia, donde la dignidad del hombre es el baluarte en el marco de un juicio público y transparente con el que el Estado debe garantizar el actuar de sus operadores. Así, cuando el ius puniendi en la praxis no cumple esas exigencias, es dable establecer que no estamos ante un debido proceso penal, sino ante un acto autoritario, trasfondo de una significación antidemocrática que evidencia la arbitrariedad de los poderes públicos (López, 2015).

El criterio jurisprudencial en cita y otros más, influyeron directamente para que la presunción de inocencia deje atrás su carácter de principio y se eleve a rango constitucional surgiendo como un derecho humano; incluso, aplicable al procedimiento administrativo sancionador, modulándolo y matizándolo, según el caso, ya que la calidad de inocente de la persona debe reconocérsele a fin de desplazar la carga de la prueba a la autoridad acusadora, en atención al derecho al debido proceso, en consecuencia que deberá 
respetarse en todos los procedimientos de cuyo resultado pudiera derivar alguna pena o sanción como consecuencia de la facultad punitiva del Estado.

Con la reforma Constitucional Federal en materia penal (2008), la presunción de inocencia que era un principio teórico se eleva a rango constitucional como garantía procesal y dispone:

Artículo 20, A...

B) De los derechos de toda persona imputada:

I. A que se presuma su inocencia, mientras no se declare su responsabilidad mediante sentencia emitida por el juez de la causa.

La presunción de inocencia comprende el derecho a ser informado de la acusación, a no confesarse culpable, la celeridad del proceso, la legalidad en el mismo, entre otros, materialmente insertos en un concepto de racional y justo procedimiento, en su extensión procesal la abarca:

a) Como una garantía básica del proceso penal el carácter previo y taxativo de esta medida cautelar proporciona la garantía de seguridad jurídica y pretende que el Juez de Control no la aplique de forma arbitraria y que en el caso de actualizarse alguno de los supuestos previstos en el Art. 19, párrafo segundo se ajuste a ellos. Para el efecto, el Código Nacional de Procedimiento Penales presume que, toda persona es inocente y será tratada como tal en todas las etapas del procedimiento, mientras no se declare su responsabilidad mediante sentencia emitida por el juez de la causa (Art. 13).

b) En su vertiente de regla de tratamiento del imputado, éste tiene el derecho a recibir la consideración y el trato de no autor o no participe del hecho que se le atribuye. En este caso, comporta la prohibición de que las medidas cautelares y en especial, la prisión preventiva, sean utilizadas como castigo -utilizar la prisión para impulsar la investigación del hecho, obtener pruebas o declaraciones, etcétera, excede los límites constitucionales-, esta calidad opera solo en supuestos donde la pretensión acusatoria tiene un fundamento razonable, ahí donde existan indicios racionales de criminalidad, de lo contrario vendría a garantizarse a costa de la libertad, un proceso cuyo objeto pudiera desvanecerse; y,

c) Como estándar de prueba influye de forma decisiva en el régimen jurídico de ésta, que debe observarse para garantizar a toda persona inocente que no será condenada sin que existan pruebas contundentes que acrediten su responsabilidad y destruyan tal presunción, justificando una sentencia condenatoria.

Cierto es, que la referida presunción puede ser vencida y desplazada por pruebas de culpabilidad aportadas por la parte acusadora, medida necesaria para el desarrollo del procedimiento, sin prejuzgar la culpabilidad jurídicamente desplazada en este caso por la inocencia constitucionalmente establecida, ya que no se agota en la virtualidad, ni en el mandato de in dubio pro reo, conforme al criterio de la Suprema Corte de Justicia de la Nación, establecido en la Jurisprudencia 1a./J. 24/2014, que interpreta la presunción de inocencia como un derecho poliédrico, bajo las vertientes: derecho humano informador; regla de trato procesal y regla de valoración de la prueba. Luego, la forma de interpretar las disposiciones que lo regulan -si atendemos a este verbo como un esfuerzo de interpretación 
ideológica, que significa mejorar el entendimiento del texto y leerlo bajo su mejor luzimplica una concatenación entre el autor y su lector a fin de perfeccionarlo, con la idea de encontrar su teleología y con ello el argumento correcto, como vía de solución a la problemática jurídico-social de falta de credibilidad y confianza a las instituciones de impartición de justicia.

Esta última regla es compatible con la llamada determinación alternativa del hecho que tiene lugar cuando existe la seguridad de que se ha cometido un delito, pero se desconocen particularidades concretas del mismo que influyan sobre su calificación jurídica, entonces el juzgador ha de establecer el hecho alternativamente, en beneficio del reo. En términos sencillos es la tipificación adecuada a los hechos ilícitos al momento de dictar sentencia, pese a la racionalidad conceptual establecida por determinados presupuestos convencionales creados en un ejercicio de ingeniería jurídico procesal (Bernal Cavero J. , 2016).

El principio de necesidad de la prisión preventiva orienta su imposición como última ratio, lo que significa en el caso de que ninguna otra medida cautelar sea suficiente para alcanzar la finalidad de esta institución. Proporcionalmente a la gravedad del hecho que se imputa.

\section{Casos de procedencia}

La prisión preventiva está regulada en el párrafo segundo del artículo 19, de la Constitución Federal en dos situaciones: 1) Cuando el Ministerio Público lo solicita al Juez de Control y 2) Cuando el Juez de Control la impone de manera oficiosa.

I. En el primer caso, se podrá solicitar la imposición de la prisión preventiva cuando otras medidas cautelares no sean suficientes para garantizar la comparecencia del imputado en el juicio, el desarrollo de la investigación, la protección de la víctima, de los testigos o de la comunidad así, también, cuando el imputado esté siendo procesado o haya sido sentenciado previamente por la comisión de un delito doloso, siempre y cuando la causa diversa no sea acumulable o conexa en los términos del Código Nacional de Procedimientos Penales (Art.30). El Juez de Control impondrá medidas cautelares a petición del Ministerio Público o de la víctima u ofendido, cuando formulada la imputación, el propio imputado se acoja al término constitucional, ya sea éste de una duración de setenta y dos horas o de ciento cuarenta y cuatro, según sea el caso o se haya vinculado a proceso al imputado (Art. 153).

II. En el segundo caso, el Juez de Control impondrá la prisión preventiva de manera oficiosa de conformidad a lo previsto en el párrafo segundo -in fine- del artículo 19 constitucional, que mediante Decreto presidencial incorporó nuevos delitos al catálogo de conductas ilícitas graves que ameritan dicha medida, para quedar como sigue:

Artículo $19 . .$.

El juez ordenará la prisión preventiva oficiosamente, en los casos de: Abuso o violencia sexual en contra de menores, Delincuencia organizada, Homicidio doloso, Femicidio, Violación, Secuestro, Trata de personas, Robo de casa habitación, Uso de programas sociales con fines electorales, Corrupción tratándose de los delitos de enriquecimiento ilícito y ejercicio abusivo de funciones, Robo al transporte de carga en cualquiera de sus modalidades, Delitos en materia de hidrocarburos, Petrolíferos o 
petroquímicos, Delitos en materia de desaparición forzada de personas y Desaparición cometida por particulares, Delitos cometidos con medios violentos con armas y explosivos, Delitos en materia de armas de fuego y explosivos de uso exclusivo del Ejército, la Armada y la Fuerza Aérea, y los delitos graves que determine la ley en contra de la seguridad de la nación, el libre desarrollo de la personalidad, y de la salud. (Diario Oficial de la Federación, 2019)

En el transitorio tercero advierte, que tratándose de los delitos en materia de corrupción mencionados entrarán en vigor a partir del nombramiento que realice el titular de la Fiscalía General de la República respecto de la Fiscalía Especializada en materia de delitos relacionados con hechos de corrupción. Mientras que, en el transitorio Cuarto ordena que contados cinco años después de la entrada en vigor el Decreto, se deberá evaluar la eficacia de dicha medida cautelar para determinar la continuidad de su aplicación, de conformidad con los criterios del Sistema Nacional de Seguridad Pública mediante informes que deberán rendir órganos jurisdiccionales, fiscalías y/o procuradurías de los Estados, así como organismos de protección de Derechos Humanos. Los informes de referencia deberán contener, al menos, los siguientes elementos:

1. Desempeño eficaz de las Unidades Estatales de Supervisión de Medidas Cautelares y Suspensión Condicional del Proceso;

2. La eficacia de las medidas cautelares aplicadas;

3. Creación y desempeño de instancias de atención integral de víctimas;

4. Implementación de sistemas de información criminal y de judicialización;

5. Resultado de la Aplicación de Mecanismos Alternativos de Solución de Controversias en Material Penal, $y$,

6. Los avances de la implementación de elementos críticos como la capacitación de los operadores de los poderes judiciales y del Ministerio Público, policía de investigación, policía preventivo, peritos, entre otros. Los parámetros para la medición de la eficacia en la implementación de los elementos críticos serán dispuestos por la ley correspondiente (sin precisar).

Como consecuencia de lo anterior se reforma, adiciona y derogan diversas disposiciones de la Ley Federal Contra la Delincuencia Organizada, de la Ley de Seguridad Nacional, del Código Nacional de Procedimientos Penales, del Código Fiscal de la Federación, y del Código Penal Federal.

\section{Finalidad}

Desde el inicio de este trabajo se hace referencia a la Declaración de Derechos del Hombre y del Ciudadano que decretó el encarcelamiento preventivo para defender la vigencia del derecho a la presunción de inocencia y que en el Pacto Internacional de Derechos Civiles y Políticos se considera la libertad subordinada a garantías que aseguren la comparecencia del acusado en el acto del juicio o en cualquier otro momento de las diligencias procesales y en su caso para la ejecución del fallo. En ese tenor, considerando que el artículo 19 constitucional claramente señala que la finalidad de esta medida cautelar solicitada cuando otras no sean suficientes-, es asegurar la comparecencia del imputado en el juicio, el desarrollo de la investigación, la protección de la víctima, de los testigos o de la 
comunidad y cuando el imputado esté siendo procesado o haya sido sentenciado previamente por la comisión de un delito doloso, siempre y cuando la causa diversa no sea acumulable o conexa en los términos del Código Nacional de Procedimientos Penales.

El ordenamiento anterior establece las circunstancias exigibles para decidir si está garantizada o no la comparecencia del imputado en el proceso y para ello el juez correspondiente tomará en cuenta especialmente: el arraigo que tenga en el lugar donde deba ser juzgado determinado por el domicilio, residencia habitual, asiento de la familia y las facilidades para abandonar el lugar o permanecer oculto. La falsedad sobre el domicilio del imputado constituye presunción de riesgo de fuga; el máximo de la pena que en su caso pudiera llegar a imponerse de acuerdo con el delito de que se trate y la actitud que voluntariamente adopta el imputado ante éste; su comportamiento posterior al hecho cometido durante el procedimiento o en otro anterior, en la medida que indique su voluntad de someterse o no a la persecución penal; la inobservancia de medidas cautelares previamente impuestas o el desacato de citaciones para actos procesales y que, conforme a derecho, le hubieran realizado las autoridades investigadoras o jurisdiccionales.

En caso de existir peligro de obstaculización del desarrollo de la investigación peligro de sustracción del imputado el ordenamiento citado establece que deberá tener presente la circunstancia del hecho imputado y los elementos aportados por el Ministerio Público para estimar como probable que, de recuperar su libertad, el imputado:

I. Destruirá, modificará, ocultará o falsificará elementos de prueba;

II. Influirá para que coimputados, testigos o peritos informen falsamente o se comporten de manera reticente o inducirá a otros a realizar tales comportamientos, $\mathrm{o}$,

III. Intimidará, amenazará u obstaculizará la labor de los servidores públicos que participan en la investigación. (Arts. 168 y 169)

Cuando se trate de la protección de la víctima u ofendido, del testigo o de la comunidad y el Ministerio Público estime que el imputado representa un riesgo inminente en contra de la seguridad de ellos, bajo su más estricta responsabilidad, ordenará fundada y motivadamente la aplicación de las medidas de protección idóneas previstas en el artículo 137 y en caso de su incumplimiento podrá imponer alguna de las medidas de apremio conforme al artículo 104 previstas en el CNPP, y tratándose de delitos por razón de género, se aplicarán de manera supletoria la Ley General de Acceso de las Mujeres a una Vida Libre de Violencia.

\section{Excepciones}

En el caso de que el imputado sea persona mayor de setenta años o afectada por una enfermedad grave o terminal, el órgano jurisdiccional podrá ordenar que la prisión preventiva se ejecute en el domicilio de la persona imputada o, de ser el caso, en un centro médico o geriátrico, bajo las medidas cautelares que procedan. De igual forma, procederá cuando se trate de mujeres embarazadas, de madres durante la lactancia. No gozarán de dicha prerrogativa, quienes a criterio del Juez de Control puedan sustraerse de la acción de la justicia o manifiesten una conducta que haga presumible su riesgo social (Art. 166).

En ningún caso queda autorizado a aplicar medidas cautelares sin tomar en cuenta el 
objeto o la finalidad de estas ni aplicar medidas más graves que las previstas en dicho ordenamiento. La prisión preventiva será ordenada conforme a los términos y las condiciones anotadas y no podrá exceder de un año, salvo que su prolongación se deba al ejercicio del derecho de defensa del imputado. Si cumplido este término no se ha dictado sentencia el imputado podrá ser liberado de inmediato mientras se sigue el proceso, sin que ello obste para imponer otras medidas cautelares (artículo 165).

Lo anterior evidencia la controversia que presenta la aplicación de la prisión preventiva con el trato de inocente, pues se sigue cuestionando, por una parte, si dicha medida cautelar quebranta el derecho de presunción de inocencia, y por la otra parte si su aplicación vulnera el estado de inocencia con la admisión de la culpabilidad por parte del imputado, para efecto de la apertura del procedimiento abreviado que implica que el acusado acepte los hechos delictivos y sea sentenciado con base en los registros de la investigación recabados por el Ministerio Público, evitando la tramitación del juicio oral con el beneficio de una pena atenuada comparada con la que aquella que se le impondría.

En el primer caso, la privación de libertad como prisión provisional se justifica para asegurar el proceso como una medida estrictamente necesaria de aplicación subsidiaria, provisional y proporcionada a los fines constitucionales que la delimitan. Para que la prisión preventiva sea compatible con la presunción de inocencia debe regularse con carácter excepcional, respetando su proporcionalidad y fijándole una limitación temporal.

En el segundo supuesto, hay que recordar que la presunción de inocencia exige que el juez o tribunal de juicio adquiera, durante el juicio la certeza de la comisión del hecho por el enjuiciado, respetando el principio in dubio pro reo que permite que la duda del juzgador o del tribunal acerca de la ocurrencia del delito que se le imputa, favorezca al reo, la falta de certeza significa que el Estado no ha sido capaz de destruir el estado de inocencia que lo ampara y por lo mismo ella debe conducir a la absolución.

El ordenamiento procesal penal establece la figura del procedimiento abreviado señalando entre los requisitos de procedencia que lo solicite el Ministerio Público para lo cual debe formular imputación y establecer los datos de prueba que lo sustentan, que el imputado consienta en su aplicación, admita su responsabilidad por el delito que se le imputa y acepte ser sentenciado con los medios de convicción que exponga la autoridad ministerial al formular la acusación (Art.201).

El Juez de Control tiene conocimiento de lo que las partes invocan, especialmente el Ministerio Público quien debe justificar que los elementos de convicción son suficientes cualitativamente para acreditar la acusación; pero necesariamente conduce al juez del conocimiento a dictar una sentencia condenatoria, sin necesidad de que las pruebas se desahoguen en juicio oral, se juzga con base en los registros de la investigación que obran en la carpeta de la autoridad ministerial. ¿Cuál es el sentido de principio de inocencia, si el Estado a través del órgano de jurisdicción acepta la confesión del imputado para aperturar el procedimiento?

Un sector de la doctrina considera que admitir la culpabilidad como elemento del delito y nexo causal y emocional que une al sujeto con el acto delictivo contraviene el principio de inocencia, el cual debe prevaler hasta el momento del enjuiciamiento, siendo necesario el 
análisis de prelación lógica todos los elementos del delito que se atribuye, al arribar al elemento culpabilidad podrá hasta entonces formular el juicio de reproche.

Otro sector lo complementa al considerar el riesgo de que el Ministerio Publico omita determinados datos de prueba que hubieren resultado idóneos para establecer el aspecto negativo de un elemento objetivo del tipo penal; independientemente de que esta nueva forma de juzgar puede convertirse en una práctica de condenar al imputado sin que dicha autoridad cumpla con la carga de probar para demostrar con certeza la culpabilidad. Es inocente sin importar la etapa del procedimiento en la que se encuentre, con protección irrestricta a sus derechos que se encuentran en el apartado B de su artículo 20 constitucional.

Se afirma también que, el hecho que se atribuye es constitutivo de delito sin que, de oficio, se advierta causa de exclusión de este. No obstante, la afirmación de delito requiere de una acción u omisión (simple o impropia) dolosa (directo o eventual) o culposa (previsible o imprevisible) que se encuentra exactamente adecuada a la descripción legal como constitutiva de un delito.

El imputado, desde el momento en que se le atribuye una conducta delictiva, goza de derechos tendientes a resguardar su persona, dignidad, libertad, honra y buen nombre, se garantiza su calidad de sujeto en la investigación y no de objeto de esta. Además, la investigación y el juicio mismo importan fases procesales que comprometen la dignidad y otros derechos de la persona, que requieren la garantía de respeto que corresponde, según los actos procesales. Es aquí donde se considera correcto citar a Ferrajoli, quien señala que debe aceptarse que no solo el abuso, sino el uso de principios que contravienen los derechos fundamentales es radicalmente ilegitimo y además idóneo para provocar el desvanecimiento de las demás garantías penales y procesales (Ferrajoli, 2004).

El derecho a la presunción de inocencia no afirma que el imputado sea realmente inocente, es decir, que no haya intervenido en la comisión de una conducta punible, el significado consiste en atribuir a toda persona un estado jurídico que exige ser considerada inocente, sin importar si el hecho de que se le atribuye. Su base angular es considerar que por naturaleza todos los hombres son inocentes, no culpables, consecuencia de lo cual es dable determinar que toda persona sujeta a un procedimiento penal no se considera responsable de la comisión de un delito hasta que exista una sentencia firme que la declare culpable.

\section{El preso provisional}

Para explicarlo se toma como punto de partida que en los establecimientos carcelarios están privados de libertad personas a las que todavía no se les ha probado su culpabilidad y los sentenciados o reos, motivo por el cual Pérez Cepeda opina que la prisión preventiva escasea de toda justificación, en la medida en que supone la más intromisión, sin que exista una sentencia firme, que ejerce el poder estatal sobre la esfera de la libertad del individuo. Por lo que es importante establecer el estatus que guarda el preso provisional a la luz de la Ley Nacional de Ejecución Penal.

El sistema penitenciario se concibe como el conjunto de normas jurídicas y de 
instituciones del Estado que tiene por objeto la supervisión de la prisión preventiva y la ejecución de sanciones penales, así como de las medidas de seguridad derivadas de una sentencia, está organizado sobre la base del respeto de los derechos humanos, del trabajo, la capacitación para el mismo, la educación, la salud y el deporte como medios para lograr la reinserción de la persona sentenciada a la sociedad y procurar que no vuelva a delinquir $\left(\right.$ Art. $\left.3^{\circ}\right)$. Rigiéndose por los principios de dignidad, igualdad, legalidad, debido proceso, confidencialidad, publicidad, proporcionalidad, etcétera. Por lo cual, las autoridades deben velar porque las personas sujetas a esta Ley (procesados y sentenciados) sean atendidas a fin de garantizar la igualdad sobre la base de la equidad en el ejercicio de sus derechos.

La ejecución de medidas penales y disciplinarias debe realizarse mediante procedimientos que permitan a las personas sujetas a una medida penal ejercer debidamente sus derechos ante la instancia que corresponda, de conformidad con los principios internacionales en materia de derechos humanos. El expediente personal de la persona privada de su libertad tendrá trato confidencial, de conformidad con la ley en la materia, y sólo podrán imponerse de su contenido las autoridades competentes, la persona privada de la libertad y su defensor o las personas directamente interesadas en la tramitación del caso salvo las excepciones establecidas en la Constitución y las leyes aplicables.

Toda intervención que tenga como consecuencia una afectación o limitación de los derechos de las personas privadas de la libertad por parte de las autoridades competentes debe ser adecuada, estrictamente necesaria y proporcional al objeto que persigue la restricción. La persona sometida a prisión preventiva o sentenciada realizará sus actividades laborales, educativas, culturales, de protección a la salud, deportivas, personales y de justicia restaurativa, de conformidad con el régimen y organización de cada Centro Penitenciario, con toda libertad de organizar sus tiempos y espacios. Su ubicación y separación se hará de conformidad con lo siguiente:

I. Las mujeres compurgarán sus penas en lugares separados de los destinados a los hombres;

II. Las personas procesadas y sentenciadas ocuparán instalaciones distintas;

III. Las instalaciones destinadas a los inimputables se ajustarán a lo dispuesto por el Capítulo IX, Título Quinto, de la presente Ley;

IV. Las personas en prisión preventiva y enejecución de sentencias por delincuencia organizada o sujeta a medidas especiales de seguridad se destinarán a espacios especiales. Adicionalmente la Autoridad Administrativa podrá establecer sistemas de clasificación de acuerdo en los criterios de igualdad, integridad y seguridad (art. 5).

La LNEP en el artículo $9^{\circ}$ establece de manera enunciativa y no limitativa los derechos que corresponden al interno durante la ejecución de la prisión preventiva o las sanciones penales impuestas, quienes gozarán de todos aquellos previstos por la Constitución y los Tratados Internacionales de los que el Estado mexicano sea parte, siempre y cuando estos no hubieren sido restringidos por la resolución o la sentencia, o su ejercicio fuese 
incompatible con el objeto de éstas. Expone también una serie de principios sustantivos y de garantías jurídicas y de procedimiento establecidas en la Declaración Universal de Derechos Humanos para asegurar el respeto en situaciones de la vida real, sin menoscabo del derecho del Estado a luchar contra el delito y a defender la sociedad, que son aplicables en el sector penitenciario. El Comité Técnico, tendrá las funciones siguientes:

I. Determinar la ubicación que le corresponde a cada persona privada de la libertad al ingresar al Centro, para los efectos del artículo 5 de la presente Ley;

II. Determinar y aplicar las sanciones disciplinarias, en estricto apego al principio de legalidad a favor de la persona interna;

III. Diseñar con participación de la persona interna, autorizar y evaluar los planes de actividades;

IV. Vigilar el cumplimiento de lo ordenado por el Juez, en lo relativo a la ejecución de la medida cautelar de prisión preventiva.

La Autoridad Penitenciaria estará obligada a prestar sus servicios a todas las personas privadas de la libertad que los requieran, ser de buena calidad y adecuarse a sus necesidades, bajo criterios de razonabilidad y no discriminación. Las personas sujetas a prisión preventiva y las personas aseguradas con fines de extradición gozarán de estos derechos desde su ingreso. Las personas privadas de la libertad podrán hacer uso voluntariamente de los servicios que ofrezca el Centro Penitenciario, con excepción de las medidas preventivas de enfermedades, de higiene y de salubridad general (Art. 32).

También estará obligada a cumplir con los protocolos que dicta la Conferencia para garantizar las condiciones de internamiento dignas y seguras para la población privada de la libertad y la seguridad y bienestar del personal y otras personas que ingresan a los Centros; entre ellos se encuentra el protocolo de ingreso, egreso y de las medidas necesarias para poner a la persona en libertad inmediata cuando la autoridad judicial así lo disponga y no exista otra causa para mantener a la persona privada de la libertad.

Otra disposición interesante radica en que las personas sujetas a prisión preventiva deberán cumplir con la resolución judicial privativa de la libertad en los Centros Penitenciarios más cercanos al lugar donde se está llevando a cabo su proceso. Mientras que, las personas sentenciadas podrán cumplir con la resolución judicial privativa de la libe los sentenciados en los más cercanos a su domicilio. Esta disposición no aplica en el caso de delincuencia organizada y respecto de otras personas privadas de libertad que requieran medidas especiales de seguridad en los términos del penúltimo párrafo del artículo 18 Constitucional.

Conforme al artículo 116 el Juez de Ejecución conocerá de controversias relacionadas con:

I. Las condiciones de internamiento y cuestiones relacionadas con el mismo;

II. El plan de actividades de la persona privada de la libertad y las cuestiones relacionadas con el mismo, que impliquen violación de derechos fundamentales;

La persona privada de su libertad podrá solicitar a dicho juez un permiso extraordinario 
de salida cuando se justifique por enfermedad terminal, fallecimiento de un pariente consanguíneo en línea ascendiente o descendiente de primer grado, cónyuge, concubina o concubinario, o socio conviviente. Esta medida no aplicará para las personas privadas de su libertad por delincuencia organizada o aquellas sujetas a medidas especiales de seguridad (Art. 145).

\section{Conclusiones}

Primera. La prisión preventiva compromete seriamente la libertad de la persona, que se justifica por la necesidad de asegurar el proceso como una medida estrictamente necesaria, de aplicación subsidiaria, provisional y proporcionada. Por lo mismo la doctrina es unánime en la exigencia de especiales resguardados para su regulación legal.

Segunda. La prisión preventiva es una medida precautoria de índole personal que crea al individuo -sobre quien recae- un estado más o menos permanente de privación de su libertad física, soportada en un establecimiento público destinado al efecto; dictada por el Juez de Control conforme a lo dispuesto por el artículo 19, párrafo segundo de la Constitución Federal que regula el carácter excepcional de la medida y establece la posibilidad de que el Ministerio Público la solicite cuando otras medidas cautelares no son suficientes para garantizar la comparecencia del imputado en el juicio, el desarrollo de la investigación, la protección de la víctima, de los testigos o de la comunidad, así como cuando el imputado esté siendo procesado o haya sido sentenciado previamente por la comisión de un delito doloso.

Tercera. La presunción de inocencia es un derecho fundamental consagrado para la práctica del Derecho penal y su ejecución, por esa razón, se pretende destacar cuán importante puede resultar su adecuada aplicación para afirmar que una persona es inocente o no lo es, sería absurdo decir que alguien es culpable sin que un juez lo determine, es decir, exige que el juez o el tribunal de la causa adquiera la certeza de que ésta cometió el delito, la falta de ella significa que el Estado no ha sido capaz de destruir el estado de inocencia que lo ampara y por lo mismo dictar la absolución. Para que la prisión preventiva sea compatible con este derecho está regulada con carácter excepcional, respetando su proporcionalidad con la gravedad del hecho imputado y fijándole una limitación temporal. Elementos que deben aplicarse especialmente por el juez en la decisión particular que debe ser debidamente fundada.

Cuarta. En el procedimiento abreviado previsto en el artículo 201 del Código Nacional de la materia, la presunción de inocencia prohíbe al juzgador considerar culpable sin mediar condena o un estado determinado, al responsable de un hecho considerado en la ley como delito, aun cuando admita la responsabilidad y acepte ser sentenciado con base en los medios de convicción que exponga el Ministerio Público que lo acusa, máxime que éste debe aportar prueba concreta capaz de generar la certeza necesaria para establecer la autoría o participación y la culpabilidad propia de una declaración judicial de condena firme. Si esto es así, es innecesario tal requisito para la procedencia de dicho procedimiento. 


\section{Fuentes de consulta}

Avalos, C. L. (2013). La prisión preventiva frente a la presunción de inocencia en el CNPP. Lima.

Beccaria, C. (s.f.). Tratado de los delitos y de las penas. Madei: Universidad Carlos III de Madrid.

Bernal Cavero, J. A. (s.f.). Determinación alternativa. Recuperado el 2016, de http://www.juecesyfiscales.org/alternativa.htm

Blinder, A. (2002). Introducción al Derecho Procesal Penal. Buenos Aires: Ad Hoc. Carrara, F. (1999). Inmoralidad de la prisión provisional. (D. Q. M., Trad.).

Cepeda, A. P. (s.f.). El régimen penitenciario.

Cuevas, L. E. (2016). Reflexiones sobre prisión preventiva. Revista Anales de Derecho., 11. Recuperado de http//revista.um.es/analesderecho

Ferrajoli, L. (2004). Derechos y Garantías. La ley del más débil. (Cuarta ed.). (P. A. Greppi., Trad.) Trotta.

Jordi, F. B. (2018). Prueba y verdad en el derecho. (2da edición. ed.). Madrid, España: Marcial Pons.

Landrove, D. G. (1984). Prisión preventiva y penas privativas de libertad, en Estudios Penales y Criminológicos (Vol. VII). Santiago de Compostela.

Ley Nacional de Ejecución Penal. (junio de 2016). Diario Oficial de la Federación. Recuperado de http://www.diputados.gob.mx/LeyesBiblio/pdf/LNEP_090518.pdf

López, M. Á. (2015). Presunción de inocencia. Derecho humano en el sistema penal acusatorio. Apéndice de jurisprudencia relacionada. México: Instituto de la Judicatura Federal.

Prisión preventiva oficiosa, Decreto de Reforma al artículo 19 de la Constitución Mexicana, Diario Oficial de la Federación. (12 de abril de 2019). Recuperado de https://dof.gob.mx/index_113.php?year=2019\&month=04\&day=12

Sandoval Pérez, E. (2016). La Duda Razonable en el Juicio Oral. Revista de Investigación 
Jurídica No. 1. Colegio de Derecho, Estudio e Investigación Jurídica., 5-14.

Sandoval Pérez, E. (2017). Presunción de inocencia como principio rector del constitucionalismo mexicano. Memoria de congreso México: UNAM-IIJ., 453-472.

Tesis Aislada núm. P. XXXV/2002. (1º de agosto de 2002). Suprema Corte de Justicia de la Nación, Novena época, Pleno, Semanario Judicial de la Federación y su Gaceta, Tomo $\mathrm{XVI}$, pág. 14. Recuperado de https://suprema-corte.vlex.com.mx/vid/tesisjurisprudencial-pleno-aislada-27196083

Universidad Nacional Autónoma de México-IIJ. (2017). Presunción de inocencia como principio rector del constitucionalismo mexicano. México: UNAM-IIJ. 